\title{
DIC Measurement of Deformation in Cracked CFRP Cross-Ply Laminates
}

\author{
M. J. Mohammad Fikry ${ }^{1, *}$ Shinji Ogihara ${ }^{1}$ and Vladimir Vinogradov ${ }^{2}$ \\ ${ }^{1}$ Department of Mechanical Engineering, Tokyo University of Science, 2641 Yamazaki, Noda-shi, Chiba-ken, 278-8510, Japan. \\ ${ }^{2}$ Newcastle University, Newcastle upon Tyne, NE1 7RU, UK. \\ *Corresponding Author: M. J. Mohammad Fikry. Email: writetofikry@yahoo.com.
}

\begin{abstract}
Digital Image Correlation (DIC) is a new non-contact method to analyze the deformation of materials that can measure displacement or strain behavior during tensile loading. In this study, DIC is used to measure the deformation of cross-ply Carbon Fibre Reinforced Plastics (CFRP) laminates and for the detection of damages in them. The objective of this study is to measure the deformation around the damages in cross-ply CFRP laminates by using the DIC system from both width and thickness directions. For this purpose, thick CFRP $\left[0{ }_{4} / 90_{24}\right]_{\mathrm{s}}$ and thinner $\left[0 / 90_{6}\right]_{\mathrm{s}}$ laminates were tested. In cross-ply laminates, usually a straight transverse crack will initially occur in 90 degrees ply followed by the following damages such as delamination, fiber fracture, and etc. To start, straight transverse cracks are induced in the laminates by using an artificial crack method. Then, X-ray radiography is used to detect the location of the straight cracks in order to be used for DIC observation to examine the strain distribution around the existed cracks. The DIC observation from the surface of the laminate around the cracks area clearly showed how strain is distributed from one crack to another adjacent crack. From the result, secondary damage mode of matrix cracking such as oblique and curved cracks also can be observed and are being discussed in this paper.
\end{abstract}

